\title{
Nursing services: an imperative to health care marketing
}

\author{
I saac D. Montoya ${ }^{1}$, Olive M. Kimball ${ }^{2}$ \\ 1. Texas Medical Center, Houston, Texas, United States. 2. CEO Emerita for The National Accrediting Agency for Clinical \\ Laboratory Sciences, Chicago, Illinois, United States. \\ Correspondence: Isaac D. Montoya. Address: 4210 West Alabama, Houston, Texas 77027, USA. Telephone: \\ 713-622-4852. Email: imontoya@affiliatedsystems.com
}

Received: January 30, 2012

DOI : $10.5430 /$ jnep.v2n4p187
Accepted: April 22, $2012 \quad$ Published: November 1, 2012

URL: http://dx.doi.org/10.5430/jnep.v2n4p187

\begin{abstract}
Nurses comprise a significant portion of the work force in any health care organization. This work force is one having the maximum exposure to patients. Further, they work hand in hand with the various departments of the organization. Though an unintended consequence of nursing care, nurses form a potential marketing tool for any health care organization. In that marketing tool role, however, there are hindrances that nurses face. These may result in an unhappy work environment and potentially impact the overall image of the organization. Added to this, nurses may not always be equipped with the knowledge and expertise they need to meet current demands of their position and thus not promote the best nursing role for marketing purposes. Interestingly, good nursing care goes hand-in-hand with good marketing efforts in spite of this being an unintended consequence. The promotion of a strong and highly capable nursing image is an important strategy in marketing of health care services.

The evolution of professional organizations and accreditation agencies has resulted in setting specific standards of practice for nursing graduates. These standards help to ensure delivery of patient care of some predetermined quality. Indirectly this offers marketability to the organization by promotion of the nursing image. At the executive level, nurse leaders can play an important role in development of nursing strategy formulation and at the same time influence strategic marketing design. This paper provides an overview of the role nurses may play in certain aspects of marketing.
\end{abstract}

\section{Key words}

Healthcare, Marketing, Nursing

\section{I ntroduction}

Over the last few decades rapid advances in healthcare knowledge and technology have created an expansion of healthcare services for routine health issues as well as for treatment of emerging issues or conditions that may have lacked treatment in the past ${ }^{[1]}$. This increased demand has fostered a continuous struggle among various healthcare providers to increase their own market share ${ }^{[2]}$. Part of this is due to a gradual shift of market share from governmental entities, professional organizations and not-for-profit health care groups to the larger for- profit companies. The government now exerts regulatory control at a distance but little direct control over the healthcare industry itself. In the United States, deregulation of advertisements of medical products, as well as relaxation of the Food and Drug Administration (FDA) rules have been 
attributed to the increased public demand for services and products. As a result, extensive marketing plans and strategies have been developed by companies to promote their products and to increase their market share ${ }^{[3]}$. Patients are more familiar with advertising and now themselves suggest specific drugs or treatments which they have seen in the media.

One of the tools used in successful marketing campaigns has been the nurse, although this has been an unintended element of the nursing role as commonly understood. However, even this element may not have been utilized by marketing professionals to the fullest extent given that nurses are in direct daily contact with patients. As such, they can easily influence the patient's perception and behaviors in terms of services and products. This paper reviews the unintended element of nurses as marketing agents.

\subsection{The meaning of marketing}

The most widely accepted definition of marketing is that of the American Marketing Association (AMA). The AMA defines marketing as "the process of planning and executing the conception, pricing, promotion and distribution of ideas, goods and services to create exchanges that satisfy individual and organizational objectives" ${ }^{[4]}$. For marketing as an activity it must satisfy the definition by controlling four variables known as the "4 P's of marketing.” The 4 P's refer to product, place, price and promotion and most marketing activities are built around these four specific variables. Berkowitz ${ }^{[5]}$ notes that "to respond to customers, an organization must develop a product, determine the price customers are willing to pay, identify what place is most convenient for customers to purchase the product or access the service, and finally, promote the product to customers to let them know it is available.” The AMA definition of marketing is applicable to the health sector as well as to other commercial sectors.

For many healthcare organizations a major marketing problem appears to be complacency ${ }^{[6]}$. That is, healthcare company leaders may believe that by monitoring patient related measures (e.g. scheduling, waiting times) as well as performance measures (e.g. revenue, expenses and profit) they are appropriately monitoring the performance of the company. It is acknowledged that these measures are important. Disney World's successful approach to complaints about congestion and long lines was the FASTPASS plan for visitors. The FASTPASS approach has since been adopted by others.

However, in a competitive health care market these measures may be absolute rather than comparative relative to performance in the larger healthcare market. This may represent what is "good enough" but not the best possible.

It is important for leaders to understand the overall dynamics of the marketplace as this can signal when it is time for an institution to make changes. Knowing a company's market share is a good indicator of changing revenue. Furthermore, increases in patient numbers may be either a result of the health care organization's strategy or an indicator of marketplace expansion ${ }^{[3]}$.

\subsection{Nurses as marketers}

The primary output of pharmacies is a product such as a medication. For medical equipment companies that output is usually a medical device such as a wheelchair or hospital bed. On the other hand, hospitals and clinics usually offer only one product and that product is a service called patient care. The principal means of day to day delivery of this care is through the nurse.

Nurses can be said to deliver two fundamental types of care:

- Care prescribed by a physician.

- Care identified by nurses themselves and within their scope of practice.

Nurses may be said to be foremost in controlling the 4P's variables, not as a planned marketing effort but rather as an unintended outcome of nursing practice. For example, in the nursing job profile nurses are in direct daily contact with 
patients dealing with care quality and services offered. They may also play a definitive role in marketing by communicating to the patient and their family accurate information about services and products. This is a form of promotion as well as a basic function of nursing care. Nurses are also strategic to the effective delivery of the services and products at the correct time and place. This can influence both the variables of pricing and of distribution. Nurses can play an important role in changing the patient's or other health professionals perceptions about healthcare services and products and may lead to behavioral changes. Indirectly, this may help in promoting better health for the patient and/or their family ${ }^{[7]}$. Like so many other professionals who provide services rather than products, these providers find themselves in an unintended marketing role.

In a hospital setting, nurses provide patient care 24 hours a day, seven days a week. Nurses deliver patient care by assessing the needs and wants of the patient, putting the recommended patient plans into action and interpreting patient outcomes. A large part of a nurse's responsibility is to coordinate delivery of care with other services including the clinical laboratory, pharmacy, dietary services, housekeeping etc. ${ }^{[8]}$. This coordination role is depicted in the figure 1 . In this role they have opportunities to advocate for improved care and influence the services provided.

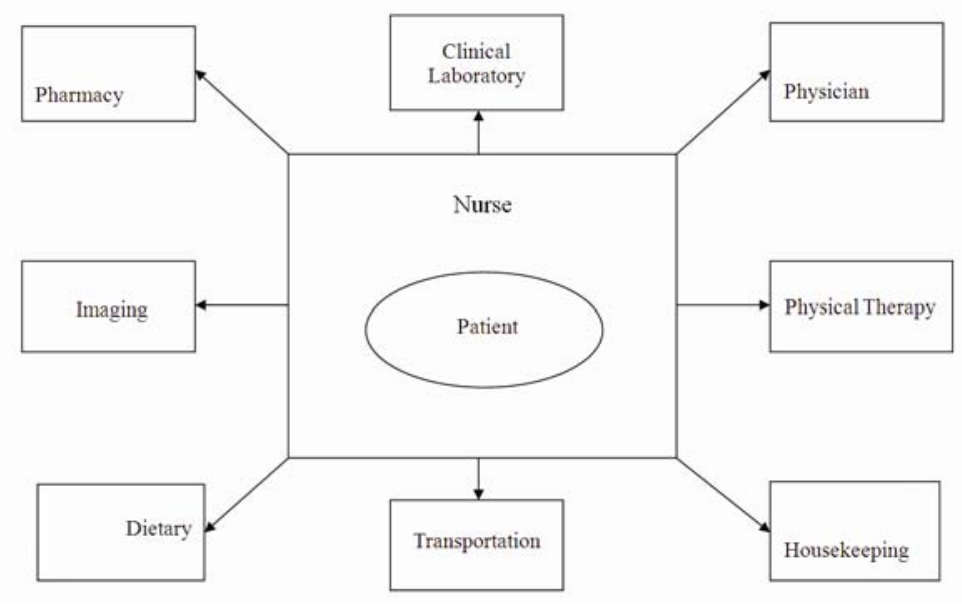

Figure 1. Depiction of Nurse Coordination with Other Providers

Contemporary hospital marketing strategies focus on providing a "humanizing" experience to patients rather than focusing on the technicalities of delivering patient care. Nurses play an important role in the implementation of this particular strategy which is often referred to as a "patient - centered care" model. For patient centered care it can be said that the nurses are in a decisive marketing position for a hospital. Often nurses market certain services or products to patients who in turn influence the physicians' decision to provide that particular service. Also, nurses engage in marketing by requesting physicians to approve a particular medication, test or therapy. The nurse's position of interacting directly with both patients and physicians makes them an automatic and powerful marketing tool ${ }^{[8]}$.

As noted, in the everyday role of providing personal patient care the nurse is also performing marketing activities. It is the nurse who oversees the consumption of services and products by patients. If a nurse observes that many patients don't respond to a particular medication or therapy s/he will most likely seek to have the physician change the type or brand of medication or therapy. Both directly and through physicians, nurses influence the decisions of the pharmacy formulary, the type and brand of medical equipment used in the hospital/clinic and to a certain extent the services offered by other providers. It becomes clear that the nurse both represents and influences a variety of markets as they carry out nursing duties. Recognizing the impact of nurses on the marketing of healthcare services and health care products, it is understandable why nurses are targeted by companies selling products and services to hospitals and clinics and why nurses have become so visible in healthcare advertisements. Conceding that there is an element of indirect communication among nurses and numerous stakeholders while acknowledging that these stakeholders may influence each other, it may be 
concluded that this interaction affects the market share of the hospital or clinic. The relationship between nurses and numerous healthcare markets is complex as depicted in figure $2^{[9]}$.

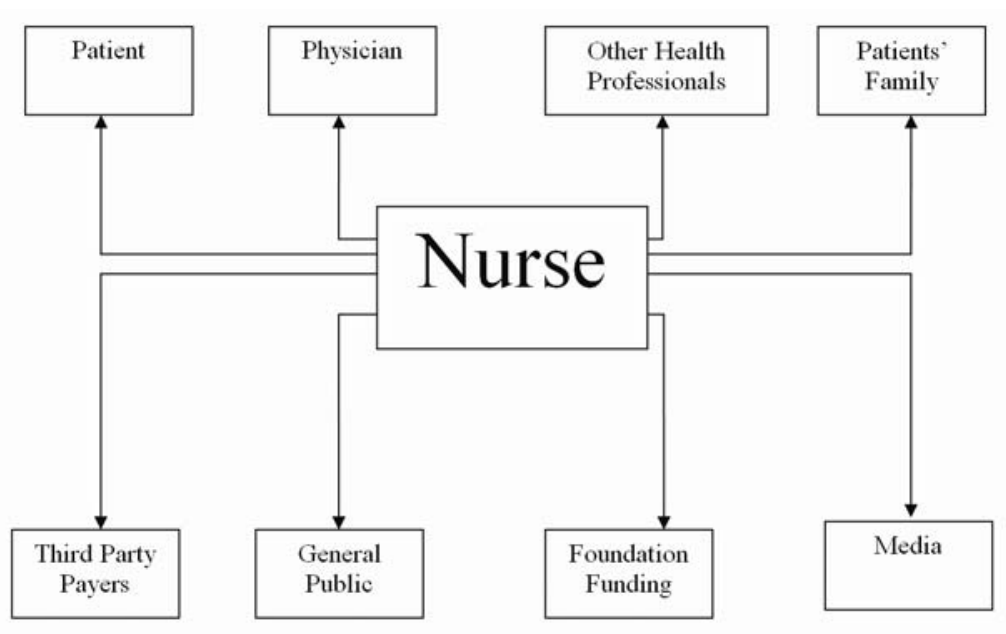

Figure 2. Relationship of nurses with various target groups

For decades pharmaceutical companies have been promoting their products to health care professionals, especially to physicians. As a means to promote these products, pharmaceutical companies have long been known to give monetary remunerations to leaders in the health care sector (including nurses) for delivering presentations that involve their products. Today physicians continue to receive compensation for serving as medical/expert advisors or consultants to medically related companies and especially to pharmaceutical companies ${ }^{[10]}$.

\section{Constraints to using nurses as marketers}

The term "burn out" in nursing is applied more often than the health care professionals would like. Frequently mentioned as reasons for the "burn out" is lack of support from administration, frustration with other service providers, perceived lack of the power to make decisions, failure on the part of the institution to recognize the loyalty of the nurses to that institution, insufficient pay, mandatory overtime and increasingly high nurse-to-patient ratios in some facilities ${ }^{[11]}$. When these problems present, nurses may not be in the position to deliver the expected quality of care nor, at times, even the most basic patient care. These conditions also serve as marketing constraints or barriers for the employers of nurses. A nurse's inability to provide a service as basic as emotional support to patients will diminish the reputation of the organization and derail any marketing efforts to increase market share. Also, in this era of technology advancement the physician's expectations of the nurse is that patients should be treated as hospitably and humanely as possible and not just in the technicalities of the care ${ }^{[8]}$. If this does not happen, it may hamper administration's desire to expand the business of the hospital/clinic. This can lead to "de-marketing" the health care organization. Again, it should be noted that all of these conditions are directly related to nursing activities but can also be considered unintended negative consequences impacting marketing efforts.

Both physicians and patients hold nurses accountable for an up-to-date and caring physical environment that is experienced by patients. If such an environment is lacking, this can lead to further frustration and decreased morale among nurses, eventually resulting in an overall negative nursing image. The fact that many of the reasons for the poor physical environment of the hospital and possible 'burn out' are beyond the control of the nurses may not be taken into account. Reasons for a poor physical environment may include overcrowding, lack of safety measures, limited resources and failure to control the patient population at times, all measures well beyond the control of nurses ${ }^{[8]}$. 


\section{Promotion of nurses in marketing and the achievement of magnet status}

While it has been noted that nurses may significantly influence the environment within health care facilities, it is important that nurses understand the image of a staff nurse that is held in the mind of a patient. This understanding can empower the nurse to reposition (adjust) the particular product or service. Such action is termed the positioning strategy by marketing professionals. The theory suggests that modification of perception of the product/service is in a patient's mind and not in the product or service itself. With this understanding, a nurse may influence patient care and can generate very positive reviews of a hospital or clinic. Organizations may use such patient reviews in marketing material. It should be noted that there are several websites that allow anyone, including physicians, to review and grade a healthcare organization. Thus, the nurse is not only an important member of the health care team but instrumental as a de facto member of the marketing team, influencing a marketing plan that may attract not only patients but physicians and other health providers to the facility.

It should be considered that until relatively recently hospitals would not use any sort of media to promote their services but would try to provide information by traditional or more interpersonal means ${ }^{[12,13]}$. The information would flow from the patients into the community as the patients talked about experiences of their stay in the hospital. The latter process is still true today but it is also recognized that the high profile of nurses and direct and daily interaction with patients makes them efficient tools for projecting a good image of the hospital ${ }^{[8]}$. Thus a chain of events is set up influencing first the nurse then the patient and then the community. Consequently, future expansion and economic success of hospitals or clinics may lie in strategies of marketing involving areas like the positioning and imaging of the institution in the market. Thus without recognizing the nurse as a tool for image building, marketing strategies related to image development may fail ${ }^{[8]}$.

Another approach to increase the sale of patient services is for the healthcare organization to achieve status as a Magnet hospital. The American Nurses Credentialing Center (ANCC- a subsidiary of the American Nurses Association) established a Magnet Recognition Program to provide a framework for higher levels of nursing practice and research in the future. As stated in ANCC literature recognition as a Magnet institution lays emphasis on the quality of health delivery and thereby increases marketability of the recognized institutions. Within the Magnet Recognition Program, there are specific guidelines set for maintaining the quality and standards for nursing practices. These guidelines and standards are defined by the American Nurse Association. However, the process of achieving this status is difficult and demands significant financial resources. Once the organization has attained the Magnet status, a high quality of delivery of patient care is guaranteed. The status can also reflect on the organization's constant effort in maintaining quality. This in turn would lead to development of a favorable image of the organization ${ }^{[14]}$.

\section{Education and nurse leaders}

To assist in development of nurses as marketing agents, in addition to the usual curriculum followed by nursing students there must be additional curricular emphasis on marketing and quality care. Familiarity with fundamentals of marketing may aid nurses to identify patients' needs so as to satisfy them by providing required services. Nurse educational programs may not sufficiently cover areas like critical appraisal, psychology, management and social science. The education providers and licensing authorities should ensure that student nurses receive exposure to commercialism and are able to practice unbiased prescribing behavior when appropriate.

The usual program of study in nursing education is limited in concepts of marketing and as a result graduates may lack critical thinking skills in that area. Thus, they would tend to accept any promotional material about drugs in an uncritical manner. They may fail to understand the strategies of marketing and lack good decision-making capabilities related to it, especially technologically related strategies. In addition, they would tend to have limited knowledge of the pharmacodynamics and pharmacokinetics of drug products ${ }^{[15]}$. Thus there may be a need for additional education for all nurses. 
Although graduate nurses appear to have sufficient clinical knowledge and practical clinical skills, leadership skills appear to be gained primarily from work experience or graduate education. Nurses involved in leadership roles must have graduate education in business or health administration. Nurses with a doctoral degree should be conversant with data collection and analysis, outcomes research and outcome management. It could further empower nurses to have knowledge of research design techniques and data analysis. So empowered, a nurse would be on a par with other service colleagues and be able to participate in activities of important strategy development ${ }^{[16]}$. Important strategy decisions of a health care organization include resource allocation and strategic future planning.

Nurse leaders, as executives and directors of other services must be part of the strategy decisions. Since many board members may not have a clinical background, input from the nursing services is important, especially when information relates to successful clinical episodes. Providing advice from the episodes for various issues such as their impact on allotment of resources is important for marketing. A marketing team can take information and ideas from inputs of the nurse leaders and thus strategize a marketing plan ${ }^{[16]}$.

Another significant responsibility of nurse leaders is that of educating patients. Their special knowledge can be shared to inform not only the patient but the general public and other health workers about current health issues. These may include, for example, acquired immune deficiency syndrome, osteoporosis, diabetes and various cancers. From time to time these are also issues of special interest to the media. Nurses are knowledgeable of related causes and impacts and must be aware of and foster accuracy in the electronic transmission of such information. Hence, nurses can become even more visible advocates of health promotion for the general public ${ }^{[9]}$.

\section{Conclusion}

In the current and predictable health care system with Health Management Organizations (HMOs) and managed health care, nurses will continue to play a pivotal role in determining future health care outcomes ${ }^{[17]}$. In order to achieve a strong and continuing presence in the marketplace, health care institutions must identify with and use their most efficient and available tool in health care marketing, nurses. By doing this they limit the need for additional marketing staff and can adopt a relatively cost effective strategy. With the experienced help of caring nurses, institutions can develop workable strategic plans and policies and effectively implement them in order to create a higher level of patient care and satisfaction ${ }^{[18]}$.

\section{References}

[1] Shublaq NW and PV Coveney. Merging genomic and phenomic data for research and clinical impact. Stud Health Technol Inform. 2012; 174: 111-5. PMid:22491122

[2] Zhu Z, BH Hen, and KL Teow. Estimating ICU bed capacity using discrete event simulation. International Journal of Healthcare Quality Assurance. 2012; 25(2): 134-44. PMid:22455178 http://dx.doi.org/10.1108/09526861211198290

[3] Derdenger, Timothy and Vineet Kumar. The Dynamic Effects of Bundling as a Product Strategy. Working Knowledge. 2012 February 22.

[4] Bennett, P.D. Dictionary of Marketing Terms. 2nd ed. McGraw-Hill Chicago: McGraw Hill, American Marketing Association, 1995.

[5] Berkowitz, Eric N. Essentials of Health Care Marketing, 3rd ed. Jones \& Bartlett Learning, 40 Tall Pine Drive, Sudbury, MA 01776. 2011.

[6] Gandolf, Stewart. When Experience Turns Into Complacency, Watch Out,” Gandolf's Marketing Magic. 2010 August 17.

[7] Rall, M M. and S M Meyer, "The role of the registered nurse in the marketing of primary healthcare services, as part of health promotion.” Curationis. 2006; 29 (1): 10-24. PMid:16817488

[8] Galimberti S, Rebora P, Di Mauro S, D'Ilio I, Viganò R, Moiset C, et al. "The SIPI for measuring complexity in nursing care: Evaluation study.” Int J Nurs Stud. 2011 Oct 13. PMid:20598691 
[9] Andreoli, Kathleen, Jack Carollo and Marian Pottage. "Marketing Strategies; Projecting An Image of Nursing That Reflects Achievement,” Nursing Administration Quarterly. 1987; 12 (4): 5-14.

[10] Civaner, Murat, Ozlem Sarikaya, Sevim U. Alicia and Gulcin Bozkurt. "Exposing Nursing Students to the Marketing Methods of Pharmaceutical Companies,” Nursing Ethics. 2008; 15 (3): 396-410. PMid:18388173 http://dx.doi.org/10.1177/0969733007088364

[11] Leiter, Michael P. Phyllis Harvie \& Cindy Frizzell. “The correspondence of patient satisfaction and nurse burnout.” Social Science \& Medicine. 2009; 47(10): 1611-1617.

[12] Goates, L. Brent. “A Compelling Public Relations Challenge for American Hospitals”. Hospital and Health Services Administration. 1976; 21 (4): 32-35.

[13] Quelch, John A. “Hospitals, Consumers and Advertising,” Dimensions in Health Health Science. 1979; 56 (11): 33-35.

[14] Anonymous. “Magnet makes an attractive marketing tool,” Health Care Strategy Management. 2006; 24 (3): 1-5.

[15] Jutel, Annemarie and David B Menkes. “Soft Targets: Nurses and the Pharmaceutical Industry,” PLoS medicine. $2008 ; 5$ (2): e5.

[16] Thorman, Kathleen E. “Nursing Leadership in the Boardroom.” Journal of Obstetric, Gynecologic, \& Neonatal Nursing. 2004; 33(3): 381-387. PMid:15180202 http://dx.doi.org/10.1177/0884217504265091

[17] Perla, Lisa. “The Future Role of Nurses.” Journal of Nurses in Staff Development. 2002; 18 (4): 194-197. http://dx.doi.org/10.1097/00124645-200207000-00005

[18] Lyon, Herbert and John M. Ivancevich. "A Behavioral Study of Nurses, Supervisors and Diagnosticians in a Hospital Setting." Decision Sciences. 1978; 9 (2): 259-72. http://dx.doi.org/10.1111/j.1540-5915.1978.tb01383.x 